\title{
Diseño del Plan de Manejo Integral de Residuos Sólidos (PMIRS) en el SECtor CaÑo Luisa (CORREgimiento de La Boquilla) distrito de Cartagena de Indias - Colombia
}

\section{Design of a plan for integral solid waste management in Caño Luisa (De la Boquilla) Cartagena de Indias - Colombia}

\author{
Diego Díaz-Vanegasa ${ }^{\mathrm{a}}$, Julieth Ulloa-Mosquera ${ }^{\mathrm{b}}$ \\ y Claudia Díaz-Mendozac
}

Recibido: 30/10/19 • Aprobado: 30/11/19

\begin{abstract}
Cómo citar: Díaz-Vanegasa, D., Ulloa-Mosquera, J., \& Díaz-Mendoza, C. (2020). Diseño del Plan de Manejo Integral de Residuos Sólidos (PMIRS) en el sector Cańo Luisa (corregimiento de La Boquilla) distrito de Cartagena de Indias - Colombia. Ciencia, Ingenierías y Aplicaciones, 3(1), 55-83.
\end{abstract}

\section{Resumen}

La elevada generación de residuos sólidos, su manejo inadecuado y deficiente gestión han sido preocupantes temas en materia ambiental, por los efectos que se producen sobre los ecosistemas y la salud pública. A partir de lo anterior surge la creciente necesidad de gestionar los residuos sólidos que son dispuestos de manera inadecuada por los habitantes de la comunidad aledaña al cuerpo de agua de Caño Luisa, que pertenece al sistema de caños internos que forman la Ciénaga de La Virgen o de Tesca en Cartagena, Colombia. El proyecto desarrollado tuvo como objetivo, a partir de una línea base ambiental de la zona en estudio, diseñar el Plan de Manejo Integral de Residuos Sólidos (PMIRS) en el sector Caño Luisa, corregimiento de la Boquilla; la metodología incluyó la caracterización de residuos sólidos generados y la propuesta de medidas de manejo tendientes a un mejoramiento

\footnotetext{
a Ingeniero Ambiental. Fundación Universitaria Tecnológico Comfenalco Cartagena, Colombia. Correo-e: diazvanegasdiego@gmail.com

b Ingeniera Ambiental. Fundación Universitaria Tecnológico Comfenalco Cartagena, Colombia. Correo-e: juliethulloa1624@hotmail.es

c Ingeniera Civil, Especialista en Ingeniería Sanitaria y Ambiental, Msc. Gestión y Auditoría Ambiental. Doctoranda en Ingeniería. Fundación Universitaria Tecnológico Comfenalco Cartagena, Colombia. Grupo de Investigación Ambiental GIA. Universidad Tecnológica de Bolívar, Colombia. Correo-e: Ing.claudia.diaz@gmail.com,cdiaz@utb.edu.co
}

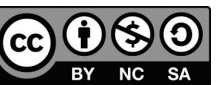

Esta obra está bajo licencia internacional Creative Commons Atribución-NoComercial-CompartirIgual 4.0 Internacional 
significativo a corto, mediano y largo plazo. Como resultado se presenta un análisis de debilidades técnico-operativas (manipulación, recolección y transporte) actuales y se proponen rutas de recolección, puntos de acopio y medidas de mitigación para mejorar las condiciones. Todo el esquema se plantea a partir de una propuesta de educación ambiental y la estructuración del PMIR desde un trabajo comunitario.

Palabras clave: residuos sólidos; plan de gestión; recolección; diagnóstico.

\begin{abstract}
The high generation of solid waste, its improper management and poor management have been worrying environmental issues, knowing how this impacts negatively on the environment and public health. Since that has been manifested the growing need to manage the solid waste that is improperly disposed by the inhabitants of the community next to the body of water of Caño Luisa, that belongs to the system of internal pipes that form the La Virgen or Tesca Swamp in Cartagena, Colombia. The objective of the project was to design the Integral Solid Waste Management Plan (PMIRS) in the Caño Luisa sector, La Boquilla district, based on an environmental baseline of the area under study; the methodology included the characterization of solid waste generated and the proposal of management measures aimed at a significant improvement in the short, medium and long term. As a result, an analysis of current technical-operational weaknesses (handling, harvesting and transportation) is presented and collection routes, collection points and mitigation measures are proposed to improve conditions. The whole scheme is based on a proposal for environmental education and the structuring of the PMIR through community work.
\end{abstract}

Keywords: Solid waste; management plan; collection; diagnosis. 


\section{Introducción}

Los residuos sólidos son un subproducto de diversas actividades y se han producido desde los albores de la humanidad; sin embargo, en un principio, sus concentraciones eran escasas y la disposición final era de fácil solución, no implicaba la ocurrencia de procesos secundarios debido a la capacidad de asimilación de la naturaleza. Con el tiempo y el avance de la tecnología se han producido cambios en los tipos de residuos generados, lo cual provoca que una inadecuada disposición los convierta en contaminantes ambientales.

De acuerdo con el Informe del Fondo de Población de Naciones Unidas (UNFPA, 2016), la población mundial ha superado los 7.400 millones de habitantes, y sigue en un comportamiento exponencial. En los últimos 55 años la población ha aumentado en un $250 \%$ (pasó de 3.034 millones en 1960 a 7.433 en 2016), se ha conglomerado, además, en los centros urbanos con mayor demanda de servicios públicos, concentrando en ciertas áreas del territorio la generación de residuos urbano-industriales y afectando, en la mayoría de los países, tanto la calidad ambiental como los recursos naturales de su entorno. Por tanto, se hace indispensable la realización y adopción de medidas de manejo de residuos sólidos urbanos, tendientes a la disminución de los impactos significativos producidos por su manejo inadecuado y a la conservación de los ecosistemas.

El proyecto de investigación desarrollado analiza el problema generado por la inadecuada disposición de residuos sólidos y propone la adopción de estrategias y acciones necesarias para la prevención y minimización en las etapas de: generación, separación en la fuente, almacenamiento, transporte, valorización y disposición final en el área de influencia del Sector Caño Luisa, constituida como una invasión ubicada al noroccidente de la Ciénaga de La Virgen. Dicha ubicación es una laguna costera ubicada sobre el costado norte de la ciudad de Cartagena y separada del 
mar por un espacio de arenas y playa perteneciente al corregimiento de la Boquilla, Colombia. La laguna posee características distintivas como su forma triangular estrecha en el norte y amplia en el sur, con anchura máxima de $4.5 \mathrm{~km}$ y una longitud de $7 \mathrm{~km}$. Además, su espejo de agua posee un área de $22.5 \mathrm{~km}^{2}$ aproximadamente y data profundidades de $1.6 \mathrm{~m}$.; cabe recalcar que en épocas de lluvia se han logrado registrar profundidades superiores a los $2.5 \mathrm{~m}$. (Ministerio de Ambiente, Vivienda y Desarrollo Territorial (MAVDT), CARDIQUE y Conservación internacional Colombia, 2004)

El artículo presenta la identificación de las características generales del territorio, entre las cuales se destacan su distribución territorial, calidad de vida de sus habitantes, características de manejo de los residuos sólidos, así como las condiciones ambientales y de salubridad de la ciénaga de La Virgen, necesarias para la construcción de una línea base acorde con la situación actual en cuanto al manejo de los residuos sólidos por parte de esta comunidad. Lo anterior se inscribe dentro de lo planteado en los Objetivos de Desarrollo Sostenible (ODS), cuyo objetivo 1 se orienta y propende por sistemas y medidas apropiadas de protección social para los pobres y vulnerables, mientras que el objetivo 6 establece la protección y el restablecimiento de los ecosistemas relacionados con el agua, en este caso los bosques de manglar y la ciénaga, mediante el apoyo y fortalecimiento de la participación de las comunidades locales en la mejora de la gestión del agua y el saneamiento ambiental. Por su parte, el objetivo 11 busca mejorar los barrios marginales, y el objetivo 12 establece lograr la gestión ecológicamente racional de todos los desechos a lo largo de su ciclo de vida, de conformidad con los marcos internacionales convenidos, y reducir de manera significativa su liberación a la atmósfera, el agua y el suelo a fin de reducir al mínimo sus efectos adversos en la salud humana y el medio ambiente. 


\section{Materiales y métodos}

El proyecto corresponde a una investigación evaluativa. Esta inicia con el estadio descriptivo en el que se pretende valorar las condiciones ambientales existentes en la comunidad, posteriormente se realiza un análisis cualitativo y cuantitativo de la información obtenida mediante trabajo de campo; a continuación, se realiza una evaluación general de toda la información para proponer las medidas de manejo requeridas para la adecuada gestión de residuos sólidos.

La etapa de recolección de información de campo se realizó mediante visitas al sector objeto de estudio, recopilación de información a través de toma de muestras y encuestas a los habitantes con relación a las temáticas de actividades económicas principales; infraestructura y cobertura de servicios públicos, además de las condiciones de saneamiento básico; uso del territorio y aspectos e impactos ambientales asociados al ecosistema de estudio. Los puntos de muestreo para toma de muestras microbiológicas y captación de residuos para caracterización, se determinaron a lo largo de un tramo de la ciénaga de La Virgen, específicamente en el sector Cańo Luisa.

En la etapa de diseño se plantean una serie de actividades encaminadas a la prevención, minimización y valorización de los residuos sólidos. Estos programas apuntan a trabajar en dos aspectos fundamentales: la adecuada gestión de los residuos sólidos y programas de educación ambiental en la comunidad.

\section{Resultados}

El área de influencia del proyecto corresponde al Sector Caño Luisa, Latitud: $10.485383^{\circ}$, Longitud: $-75.489233^{\circ}$ tiene $0.8 \mathrm{~km}$ de longitud y profundidad promedio de $1.03 \mathrm{~m}$ (según batimetría realizada en septiembre 2017), constituida como una invasión ubicada al noroccidente de la Ciénaga de La Virgen, Distrito de Cartagena de Indias en el corregimiento de la Boquilla; como se muestra en la figura 1 . 


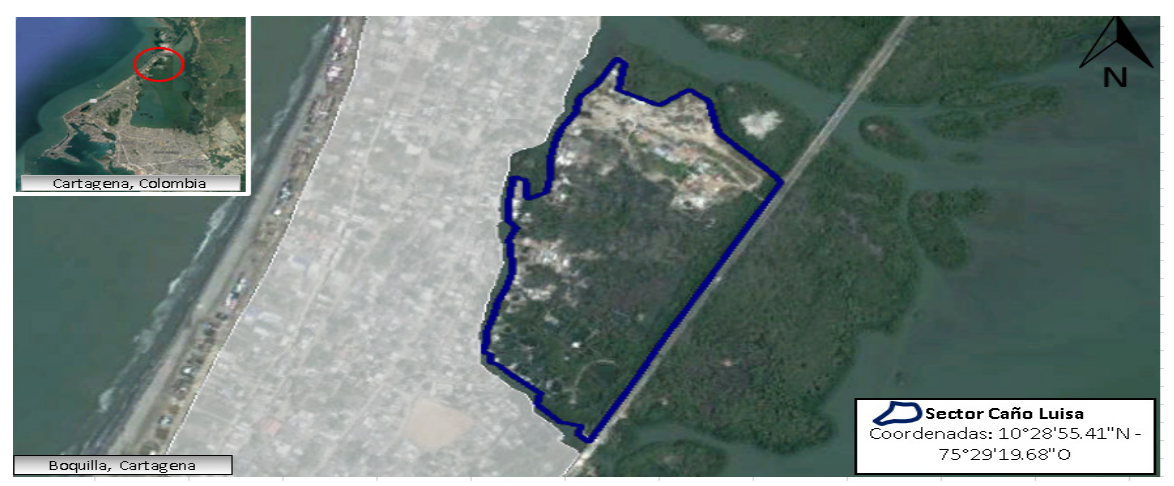

Figura 1. Localización geográfica del sector Caño Luisa

Fuente: elaboración propia a partir de la herramienta Google Earth.

La caracterización socio-económica realizada se muestra en la figura 2; los resultados del estudio evidencian que el corregimiento de La Boquilla se encuentra dividido en tres sectores principales: Sector Abajo, Sector Centro y Sector Arriba; este último está conformado por subsectores conocidos como Bogotá, Florida y el Manglar. El sector Caño Luisa se encuentra en la zona sur-este del Sector Arriba, a través de un tramo hídrico perteneciente a la Ciénaga de La Virgen; territorio natural, ecosistema de manglares donde mas del $50 \%$ de la poblacion asegura haber residido entre 1 y 10 años en la zona; en el territorio se encuentran asentadas aproximadamente 76 viviendas con un estimado de 228 habitantes de escasos recursos, de acuerdo con el levantamiento de información primaria realizado.

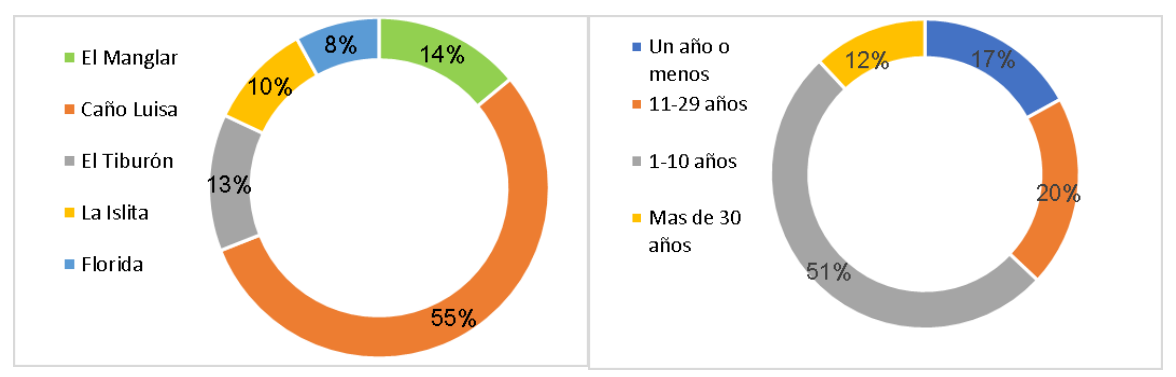

2.1 Subdivisión de la Boquilla

2.2 Tiempo de residencia 


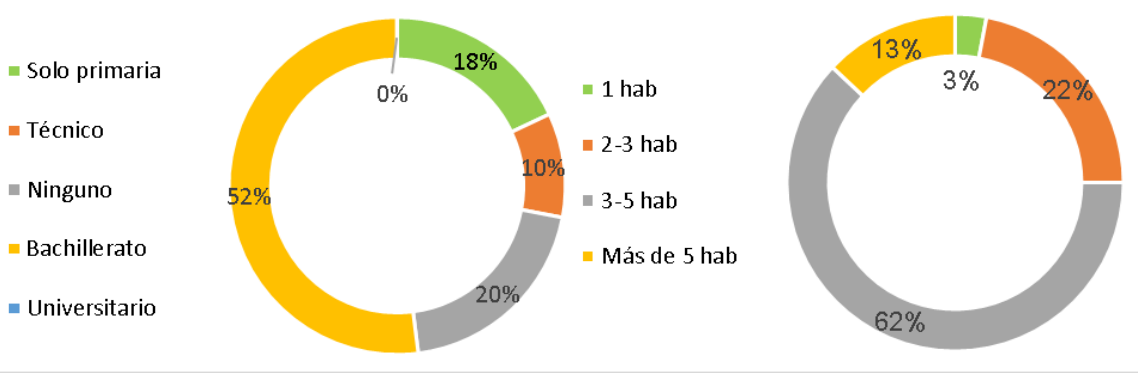

2.3 Nivel de escolaridad

2.4 Habitantes por vivienda

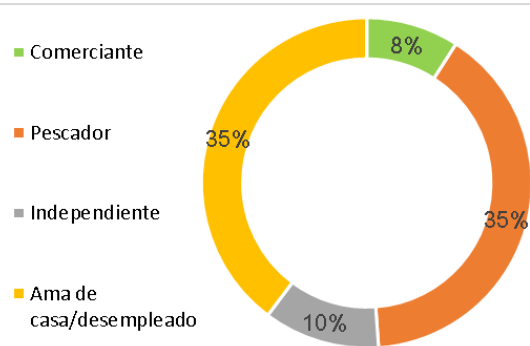

2.5 Actividad económica

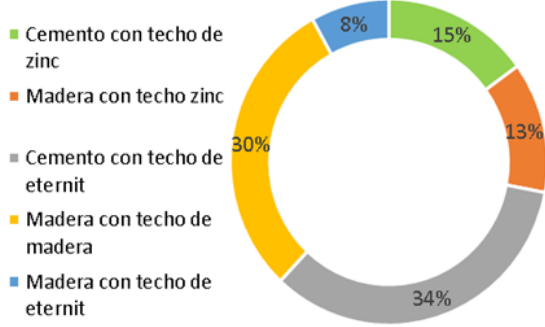

2.6 Infraestructura de vivienda

Figura 2. Caracterización socio-económica de la zona de interés

Por lo general las viviendas están construidas con materiales de madera y techo de eternit; siendo en su mayoría de carácter propio (78 \%), habitadas en promedio por 3 personas y siendo las actividades reportadas la pesca, servicios en el hogar y desempleados.

De acuerdo con la información primaria obtenida, el nivel de educación se encuentra distribuido en Educación secundaria (63\%), Educación técnica (16\%), y el $21 \%$ no posee ningún nivel educativo. Por la naturaleza del territorio, la comunidad no cuenta con servicios públicos instalados directamente por una empresa prestadora de servicios, por lo que se abastece de agua potable y de energía eléctrica a través de conexiones informales desde la zona legalmente constituida del corregimiento de la Boquilla hasta las viviendas de la invasión. Además, el servicio de gas es a través de cilindros de gas propano. 
El diagnóstico ambiental se realizó teniendo en cuenta las condiciones de la Ciénaga en el territorio y los aspectos ambientales que generan impactos sobre los recursos agua, aire, suelo, flora y fauna. De acuerdo con la información contemplada en el Plan de Ordenamiento Territorial de Cartagena (POT, 2001), el uso actual del suelo en la franja urbana de la Boquilla es de tipo mixto 2 (comerciales, residenciales, turísticos y otros, sin mantener el grado de compatibilidad necesario entre ellos, se presentan simultáneamente en los barrios de la ciudad como producto de procesos espontáneos y sin control, lo cual ha generado un gran deterioro en sus zonas residenciales y, en general, en toda la zona urbana). El sector Caño Luisa se constituye como una zona verde de protección a lo largo de parches de manglar de la Ciénaga de La Virgen, donde se han constituido numerosas viviendas invasoras que han dado como resultado $1.902 \mathrm{~m}^{2} \mathrm{de}$ área desprovista de manglares y otras especies arbóreas características del territorio, en menos de 10 años. El riesgo de inundación por ascenso del nivel del mar, se constituye como el más relevante entre el listado del POT. La figura 3 muestra las consideraciones incluidas en el POT de Cartagena de acuerdo con el uso de suelo en la zona de influencia del proyecto.
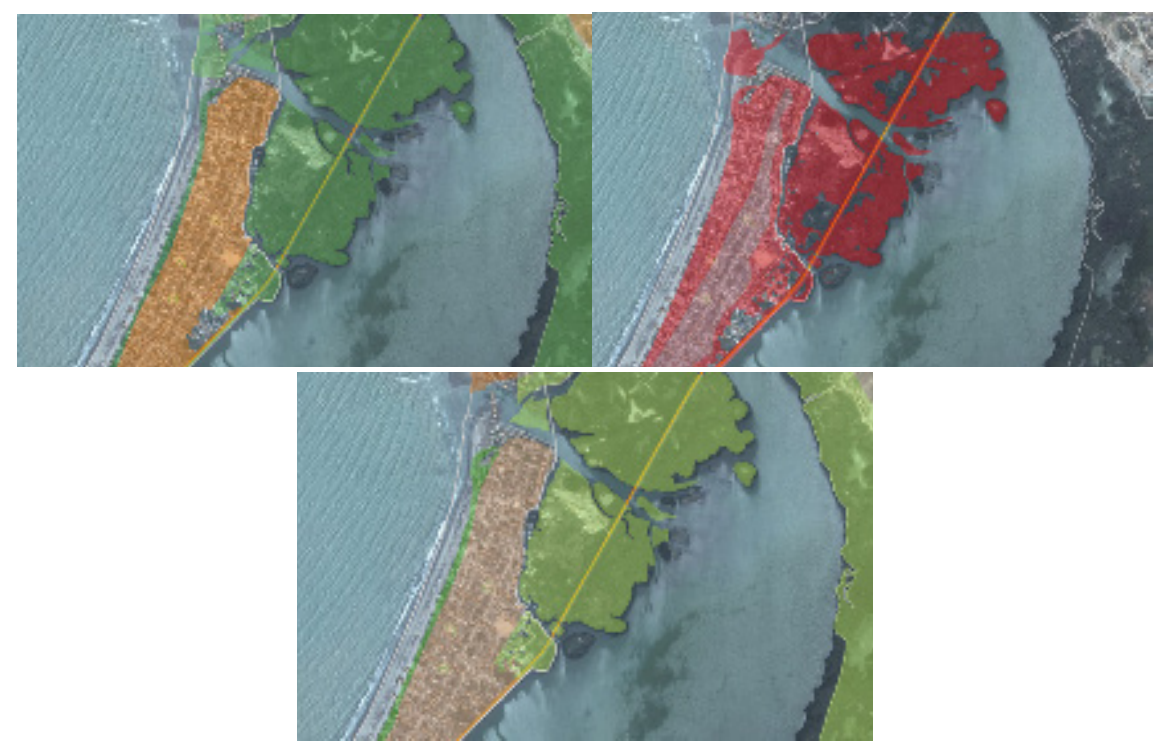

Figura 3. Uso del Suelo (POT Cartagena, 2001). Izquierda: uso del suelo: mixto 2 (naranja), zona verde de protección (verde). Centro: riesgo de inundación por ascenso del nivel del mar. Derecha: categoría de "Mejoramiento Integral Total" 
Se elaboró una línea de tiempo a partir de imágenes satelitales, donde se evidencian áreas desprovistas de vegetación propia de manglares, esta zona ha sido utilizada para la construcción de viviendas no legales, sin tener en cuenta los riesgos asociados a fenómenos de inundación y de expansión no planificada. La línea de tiempo se muestra en la Figura 4.

\section{Enero de 2012}

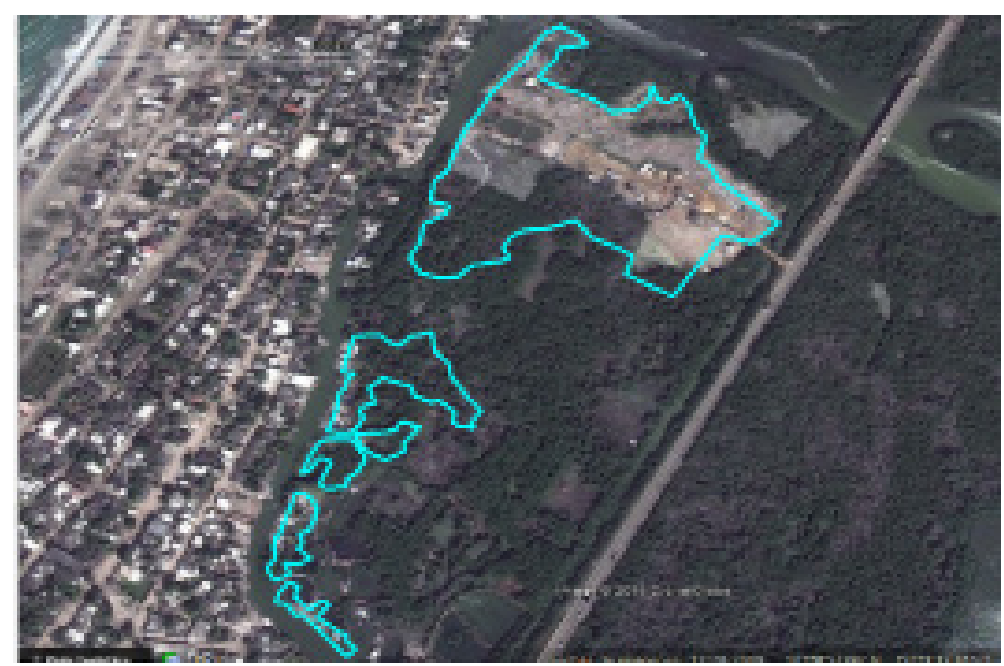

Febrero de 2017

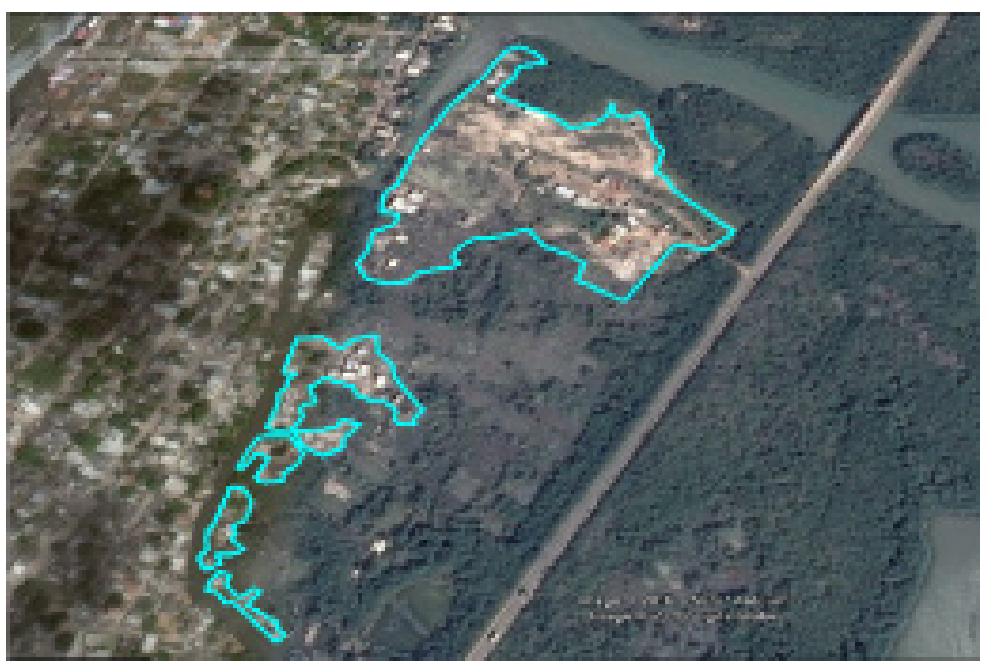

Figura 4. Línea de tiempo ocupación de suelo por zona de invasión 
El asentamiento de la comunidad, de manera no formal, en la zona de influencia directa de Caño Luisa ha traído como consecuencia múltiples problemáticas ambientales, la más fuerte identificada es la asociada a los residuos sólidos que son dispuestos de forma inadecuada en el cuerpo de agua y zonas aledańas, tal como lo muestra la figura 5.

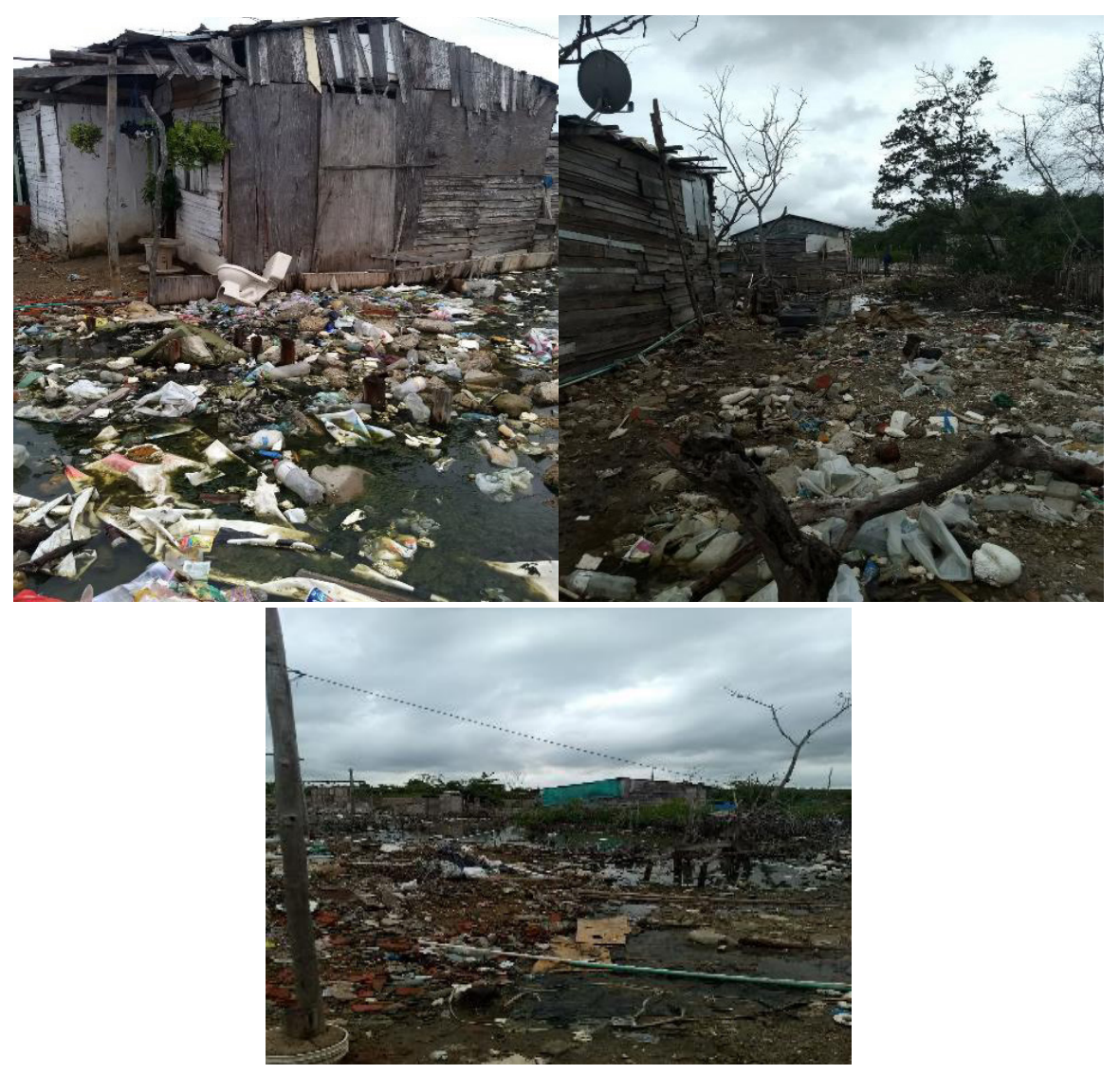

Figura 5. Inadecuada disposición de residuos sólidos en zona de influencia. Izquierda: viviendas informales con vertimiento residuos sólidos a Cańo Luisa. Centro: zonas deforestadas, cambio de uso de suelo. Derecha: rellenos con residuos sólidos

Para la identificación de impactos significativos de carácter negativo, se hizo uso de una matriz de valoración general del territorio; a partir de las características o comportamiento cultural de la comunidad objeto de estudio, frente a la disposición final de los residuos sólidos, obteniéndose como resultados los mostrados en la tabla 1. 
Tabla 1. Impactos ambientales asociados al manejo de los residuos sólidos

\begin{tabular}{|c|c|c|c|c|c|c|c|}
\hline \multirow[t]{3}{*}{ Factor ambiental } & \multicolumn{6}{|c|}{ Impacto Significativo carácter negativo } & \multirow{3}{*}{$\begin{array}{c}\text { Evaluación } \\
\text { general }\end{array}$} \\
\hline & \multicolumn{2}{|c|}{$\begin{array}{c}\text { Área de } \\
\text { influencia }\end{array}$} & \multicolumn{2}{|c|}{ Temporalidad } & \multicolumn{2}{|c|}{ Permanencia } & \\
\hline & $\mathrm{D}$ & ID & $\mathrm{CP}$ & LP & $\mathrm{R}$ & IR & \\
\hline $\begin{array}{c}\text { Salud } \\
\text { (comunidad) }\end{array}$ & $\mathrm{X}$ & & $\mathrm{X}$ & & $\mathrm{X}$ & & 3 \\
\hline $\begin{array}{l}\text { Bienestar } \\
\text { (recreación) }\end{array}$ & $\mathrm{X}$ & & $\mathrm{X}$ & & $\mathrm{X}$ & & 2 \\
\hline $\begin{array}{l}\text { Valor económico y } \\
\text { propiedades }\end{array}$ & $\mathrm{X}$ & & & $\mathrm{X}$ & $\mathrm{X}$ & & 3 \\
\hline Paisaje & $\mathrm{X}$ & & & $\mathrm{X}$ & $\mathrm{X}$ & & 3 \\
\hline $\begin{array}{l}\text { Calidad de agua } \\
\text { superficial }\end{array}$ & $\mathrm{X}$ & & & $\mathrm{X}$ & $\mathrm{X}$ & & 3 \\
\hline Calidad del suelo & $\mathrm{X}$ & & $\mathrm{X}$ & & $\mathrm{X}$ & & 3 \\
\hline Tráfico & $\mathrm{X}$ & & $\mathrm{X}$ & & $\mathrm{X}$ & & 3 \\
\hline Especies vegetales & $\mathrm{X}$ & & & $\mathrm{X}$ & $\mathrm{X}$ & & 3 \\
\hline Aspectos culturales & $\mathrm{X}$ & & & $\mathrm{X}$ & $\mathrm{X}$ & & 2 \\
\hline \multicolumn{5}{|c|}{$\begin{array}{l}\text { Consideraciones: } \\
\text { Directa (D): radio }>1.000 \text { metros a la redonda } \\
\text { Indirecta (ID): radio }<1.000 \text { metros a la redonda } \\
\text { Corto plazo (CP): impacto no dura más de } 3 \text { ańos } \\
\text { Largo plazo (LP): impacto supera } 3 \text { años } \\
\text { Reversible (R): posible anular o mitigar el impacto } \\
\text { Irreversible (IR): no es posible anular el impacto }\end{array}$} & \multicolumn{3}{|c|}{$\begin{array}{l}\text { 0- Indiferente } \\
\text { 1- No requiere medidas } \\
\text { 2- Poco riesgo, se requieren medidas } \\
\text { 3- Muchos o grandes riesgos, se } \\
\text { requieren medidas de protección }\end{array}$} \\
\hline
\end{tabular}

Otros factores ambientales asociados y que definen la calidad de vida, salud actual de las personas, calidad del agua tanto de la Ciénaga de La Virgen como del agua de consumo, proliferación de vectores producto de la contaminación por vertimiento de aguas residuales y por disposición de residuos sólidos en botaderos satélites se muestran en las figura 6 , donde se puede observar que la mayor problemática ambiental identificada por la comunidad se asocia a inundaciones (22\%) y disposición inadecuada de residuos sólidos (18\%); estos residuos son en una gran proporción (37 \%) utilizados en rellenos informales de la Ciénaga; también se reportaron problemáticas asociadas a convivencia con animales y disposición inadecuada de excretas. 
6.1 Problemáticas ambientales
Inundación
Ruido
Disposición inadecuada de residuos sólidos
- Tala de manglares
- Vertimiento de residuos liquidos
- Generación de material particulado
Humo por quema de residuos
- Generación de olores ofensivos

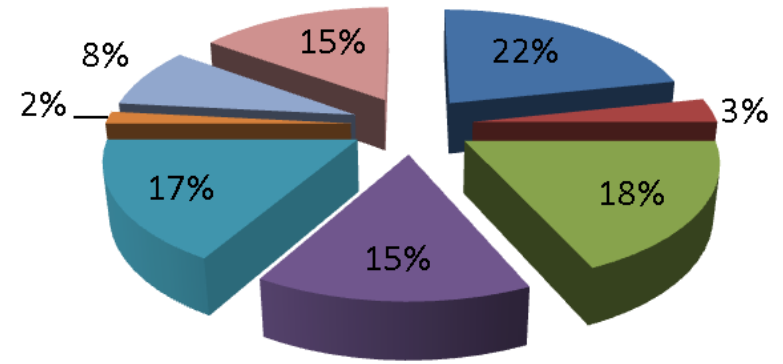

6.2 Manejo final de los residuos sólidos

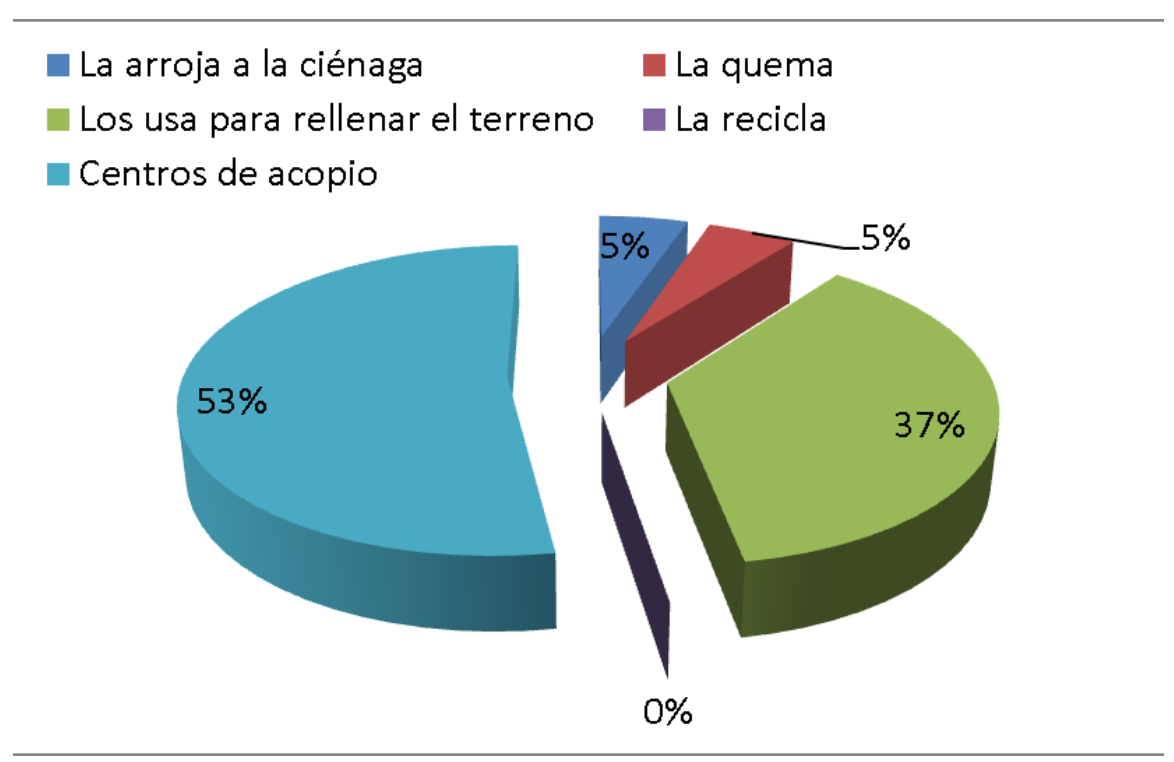




\subsection{Animales en viviendas}

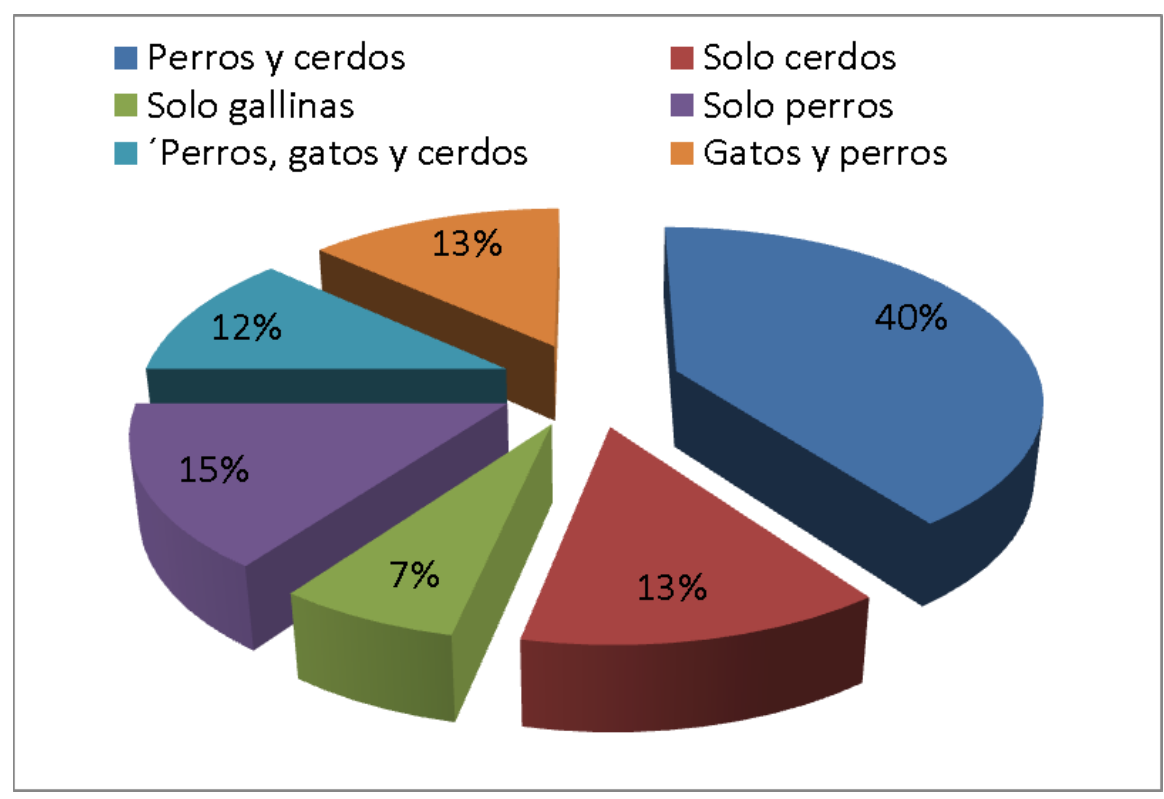

6.4 Disposición excretas animales

En la letrina

- Campo abierto cerca a la casa

Bolsa de basura general de la casa $\square$ No tiene animales
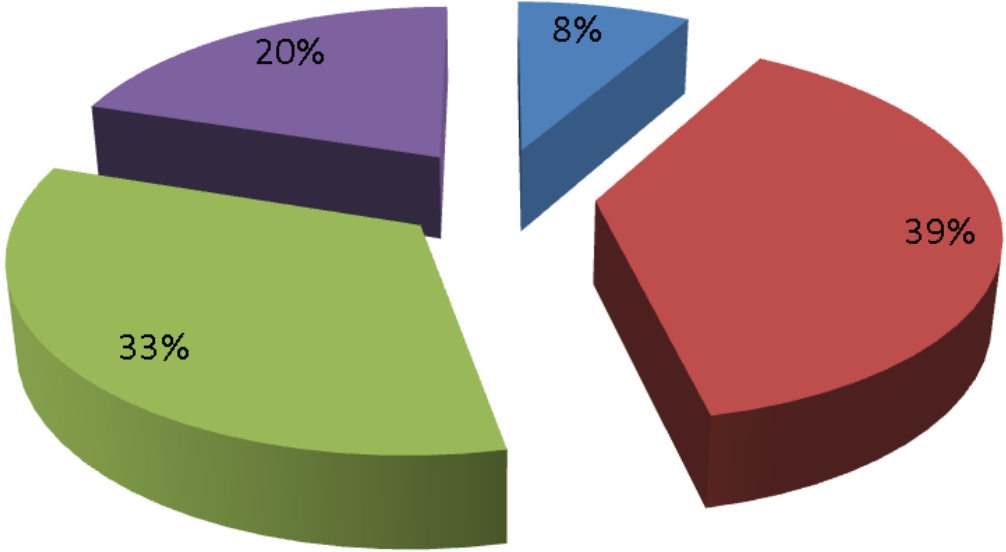

Figura 6. Factores ambientales asociados que definen la calidad de vida 
En el contexto ambiental se considera de afectación directa a aquellas comunidades que se encuentran en un círculo de 1.000 metros de radio, tomando como centro la instalación donde se realiza la disposición final de los residuos sólidos, y de afectación indirecta, aquellas que están ubicadas fuera de este (Ministerio de Ambiente, Vivienda y Desarrollo Territorial, 2005). De acuerdo con la figura 7 , los resultados obtenidos evidencian a la comunidad del sector Caño Luisa como de afectación directa, dentro del radio de 1.000 metros; además, se identificaron botaderos satélites a lo largo del sector, dispuestos en su mayoría en los patios y frentes de las viviendas ubicadas en la franja del cuerpo de agua; representando una fuerte problemática ambiental.

Dentro de las fuentes de agua superficiales identificadas, se resaltaron aquellas que se encuentran a 500 metros a la redonda como de afectación FUERTE, respecto al sitio de disposición final, y aquellas que estén por fuera del rango, como de afectación MODERADA. (Ministerio de Ambiente, Vivienda y Desarrollo Territorial, 2005) Cabe resaltar que no se encontraron fuentes de agua subterráneas para el alcance del presente proyecto. De acuerdo con la figura 7, se identificaron fuentes de agua afectadas por la disposición final de los residuos sólidos de zonas aledañas.

Comunidades afectadas directa e indirectamente por disposición final de residuos sólidos

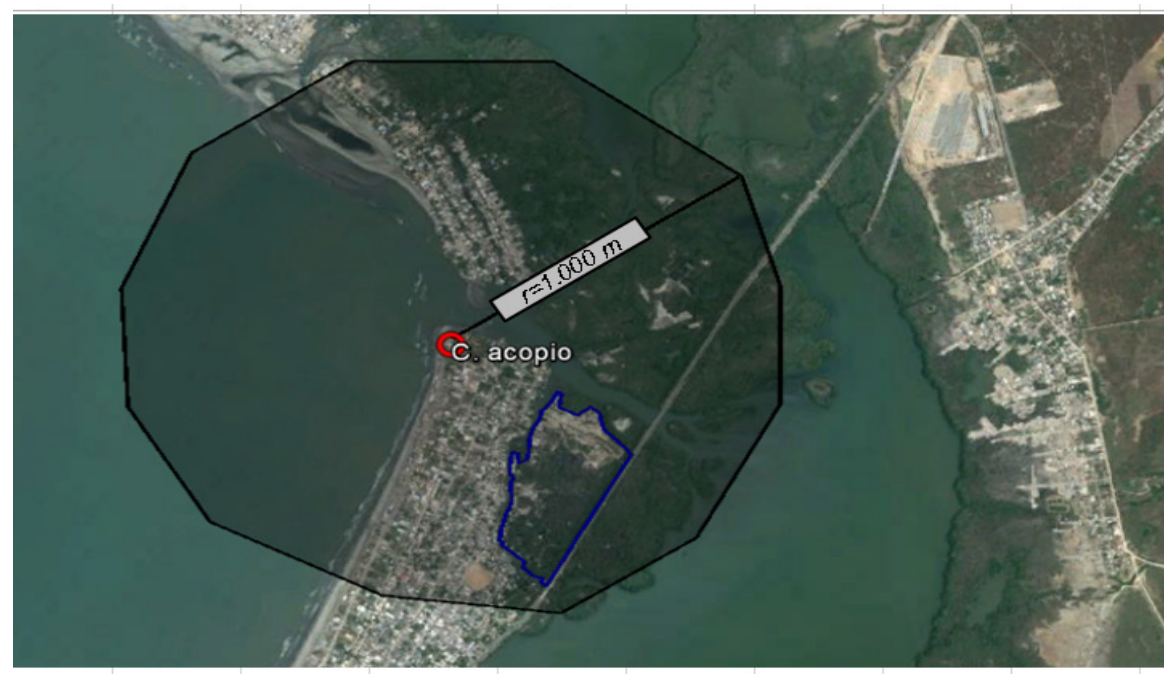


Fuentes de agua afectadas por disposición final de residuos sólidos

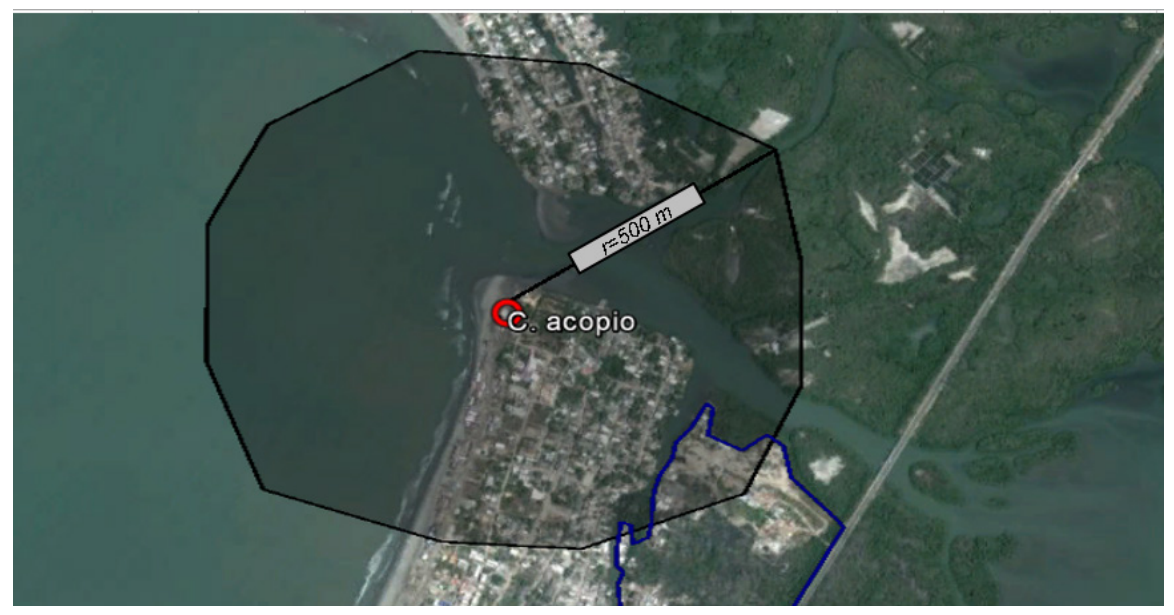

Figura 7. Fuentes de aguas afectadas y radio de influencia

Se evaluó la presencia de mohos ambientales en la zona de influencia del sector Caño Luisa, donde la presencia de residuos sólidos ejerce mayor presión y genera olores ofensivos. Lo anterior afecta la calidad de vida de la comunidad en la zona de influencia.

Se tomaron cinco muestras distribuidas a lo largo de la zona de estudio, como lo indica la figura 8. Se identificaron cinco géneros de hongos, previamente aislados mediante cultivos de Agar, tal como lo muestra la figura 9: a) Cladophialophora sp.; b) Aspergillus sp: se presume de un $A$. flavus; c) Rhizopus sp.; d) Fusarium Sp.; e) Scopulariopsis sp. Algunos de ellos, de acuerdo con la literatura revisada, se han descrito como agentes responsables de infecciones cutáneas y queratitis (Schell, 2003).

Los puntos más críticos en cuanto a presencia de hongos fueron el 4 y 5 , con presencia de varios géneros, entre los más relevantes se resaltan: Aspergillus Niger, A. flavus, A. sclerotiorum, Fusarium solani, A. clavatus y Trichophyton. El contacto del ser humano con estos hongos puede causar onicomicosis. Además, esporádicamente se ha relacionado como agente de endocarditis, queratitis y de infecciones invasoras (De Hoog, GS, Guarro, J, Gené, J, Figueras, MJ., 2000) 


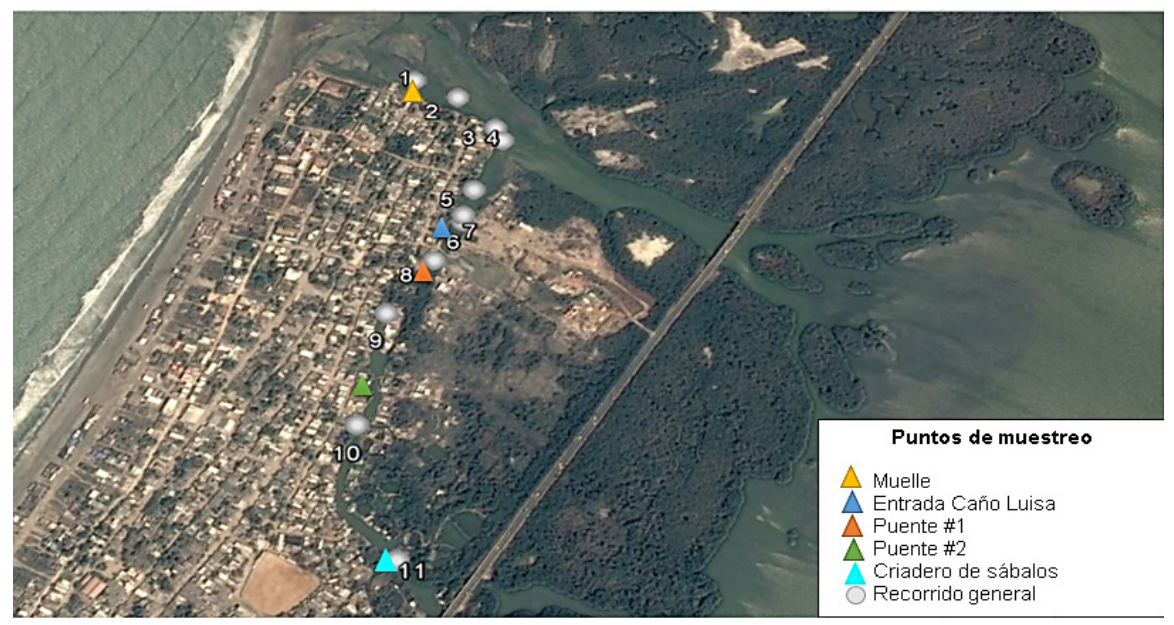

Figura 8. Puntos de muestreo de mohos ambientales

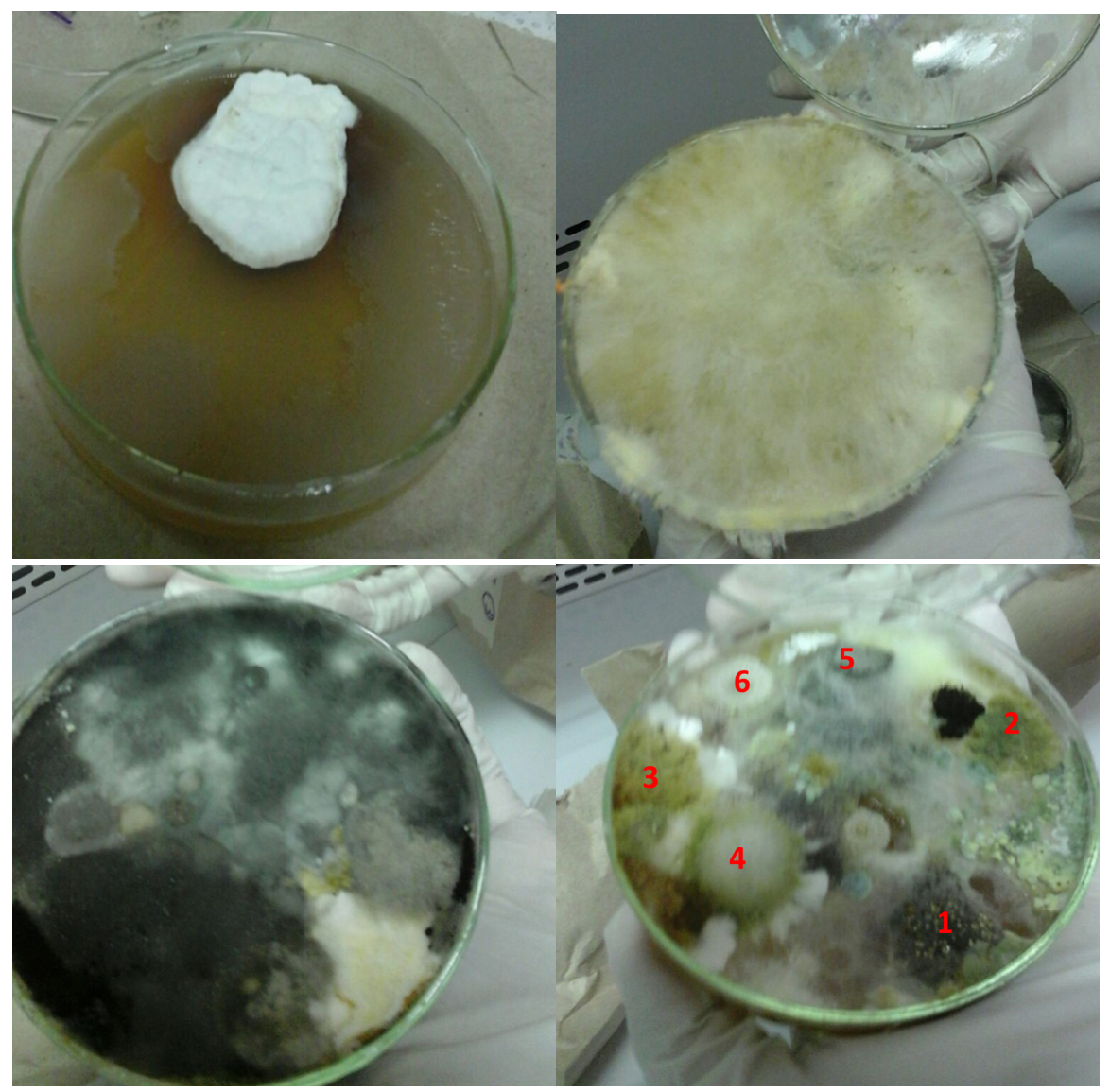




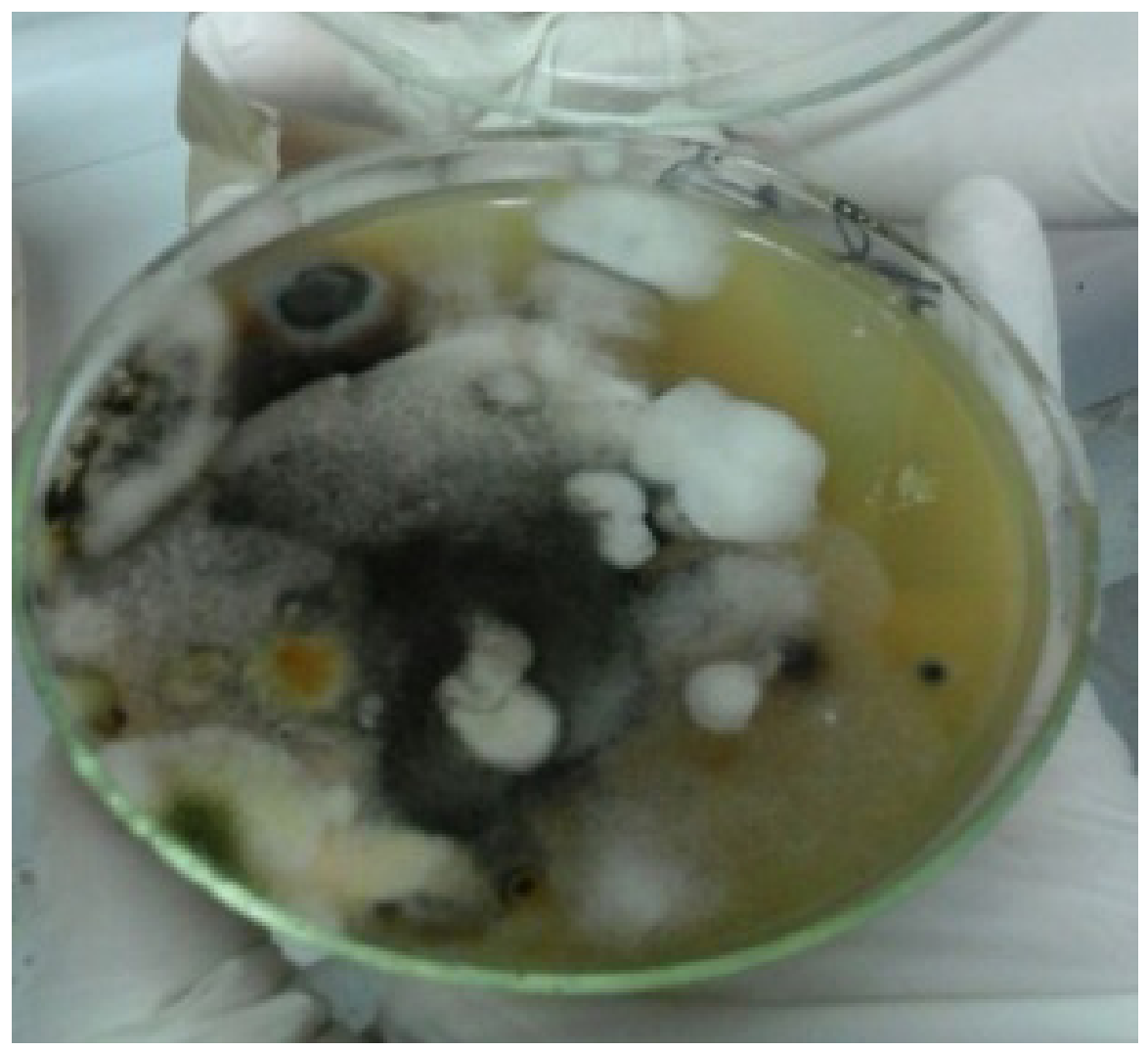

Figura 9. Mohos ambientales; a) Punto \#1 Cladophialophora sp; b) Punto \#2 Aspergillus sp: A. flavus; c) Punto \#3 Rhizopus sp; d) Punto \#4 Fusarium sp; e) Punto \#5 Scopulariopsis sp.

La comunidad aledaña al sector Caño Luisa, no dispone de un servicio de aseo directo para la recolección y disposición final de sus residuos, algunos miembros de la comunidad se han organizado para hacer recolección informal de los residuos sólidos que son arrojados directamente al cuerpo de agua; para efectuar la caracterización de residuos sólidos se determinó un aproximado de las viviendas en la zona de influencia y la ocupación promedio de tres personas por unidad habitacional. Se realizó un análisis estadístico para la selección de la muestra representativa de encuestas a realizar, obteniendo como resultado una muestra de 60 para un nivel de confianza del $90 \%$. Se determinó la producción per cápita, la caracterización física de los residuos (método de cuarteo) y la densidad de los residuos. 
La producción per cápita calculada en la zona de estudio se muestra en la tabla 2; según el informe de la Superintendencia de Servicios Públicos Domiciliarios (2018), la cifra de producción per cápita para Bolívar está alrededor de $0,85 \mathrm{Kg} / \mathrm{hab} /$ día, si comparamos con la encontrada en la comunidad, a pesar de estar por debajo, el potencial impacto que se genera es el vertimiento de dicha producción al cuerpo de agua.

Tabla 2. Producción per cápita de residuos sólidos generados por la comunidad

\begin{tabular}{|c|c|c|}
\hline Variable & Valor & Fórmula \\
\hline $\mathrm{Kg} /$ viv* $^{*}$ día & 1,39 & $\begin{array}{r}\mathrm{PPC}=(316,01 \mathrm{Kg}) /(76 \text { viviendas } \times 3 \text { días } \\
\text { de almacenamiento })\end{array}$ \\
\hline $\mathrm{Kg} / \mathrm{hab}^{*}$ día & 0,46 & $\begin{array}{c}\mathrm{PPC}=(316,01 \mathrm{Kg}) /(228 \text { habitantes } \times 3 \text { días } \\
\text { de almacenamiento })\end{array}$ \\
\hline $\mathrm{Kg} /$ hab*mes $^{*}$ & 13,86 & $\mathrm{PPC}=\left(0,46^{*} 30\right.$ días $)$ \\
\hline
\end{tabular}

Fuente: elaboración propia.

Se realizó la caracterización física de los residuos sólidos mediante método de cuarteo; se analizaron los dos tipos de disposición presentes en la zona: los arrojados inadecuadamente en el cuerpo de agua ( 2 cuarteos como muestra representativa) y los dispuestos por la comunidad en el punto de acopio (3 cuarteos como muestra representativa). La figura 10 muestra la distribución porcentual por tipo de residuos dispuesto de manera inadecuada en el cuerpo de agua; la gráfica también muestra la distribución porcentual por tipo de residuos entregado para disposición por las viviendas. Se puede observar que la tendencia en la producción de las viviendas, en materiales ordinarios y plásticos es lo que se evidencia en el cuerpo de agua, lo que permite inferir que el deterioro ambiental de la Ciénaga de La Virgen se encuentra influenciado por el manejo inadecuado de los residuos sólidos y el nivel bajo de educación ambiental en las comunidades aledańas. 
10.1 Porcentaje de residuos sólidos en el cuerpo de agua

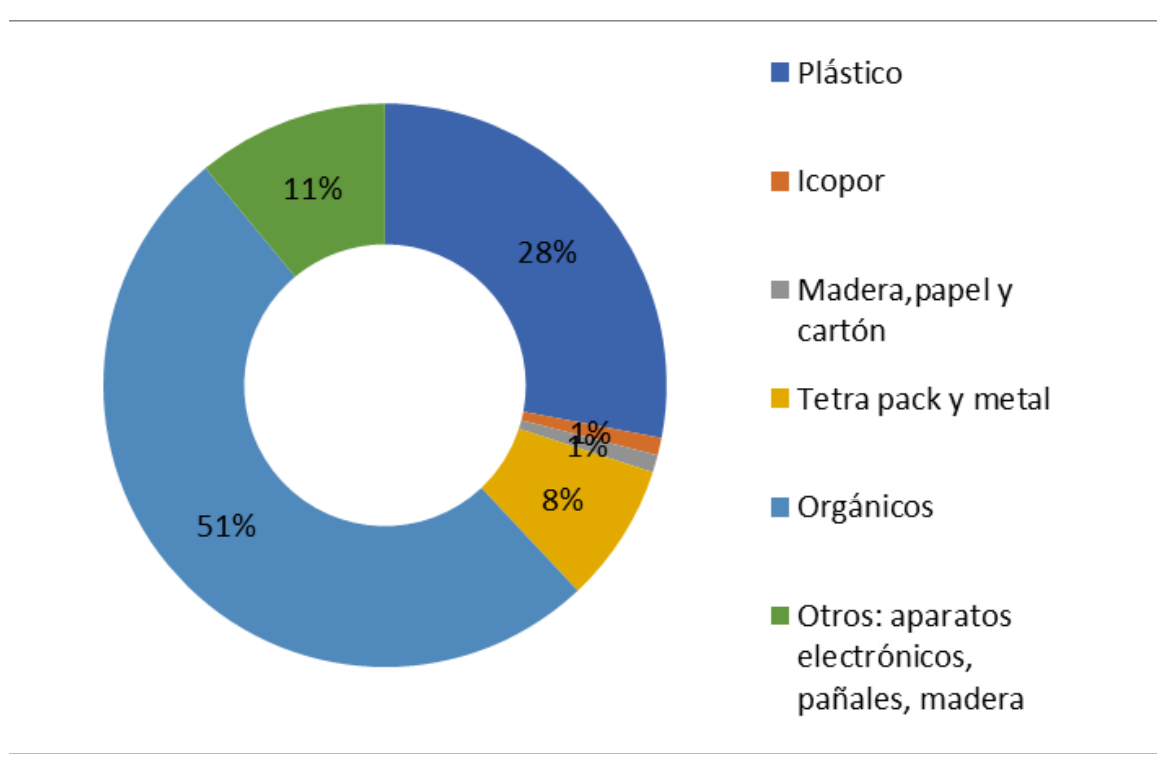

10.2 Porcentaje de residuos sólidos en viviendas

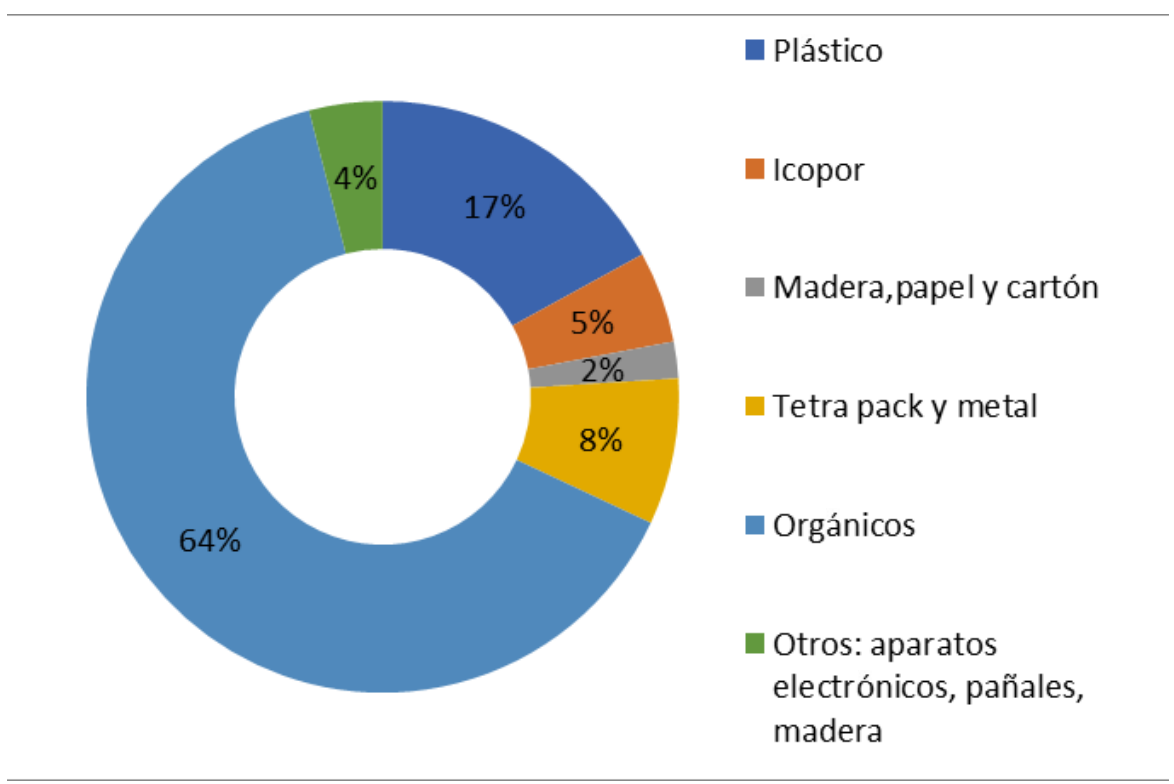

Figura 10. Resultados de la caracterización de los residuos sólidos. a) Distribución porcentual residuos sólidos en el cuerpo de agua. b) Distribución porcentual residuos sólidos en las viviendas 
Dentro de las propiedades físicas a considerar en la gestión integral de residuos sólidos se encuentran el peso, el porcentaje de humedad y el peso específico (o densidad). Usualmente se utilizan unidades de peso (gramos, kilogramos, toneladas, etc.) y se hace referencia a la presencia o no de humedad. El peso húmedo corresponde al peso de los residuos tal y como se generan (Municipalidad Distrital de Comas, 2014). La densidad de los residuos sólidos en el área de estudio se estimó en

$$
\rho_{\mathrm{rs}}=\frac{\mathrm{P}_{\text {neto de los residuos sólidos }}}{\mathrm{V}_{\text {del recipiente en } \mathrm{m}^{3}}}=73,25 \mathrm{~kg} / \mathrm{m}^{3}
$$

Se analizó el estado de cumplimiento del Decreto Ley 2981 de 2013, que en Colombia rige la prestación del servicio público de aseo, en cuanto a las variables contempladas por este con relación a características de las cajas de almacenamiento, sitios de ubicación para las cajas de almacenamiento, recolección en zonas suburbanas, rurales y centros poblados rurales. El análisis arrojó que el $60 \%$ no cumple con el decreto, el $27 \%$ cumple parcialmente y el $13 \%$ cumple a satisfacción con lo estipulado por ley.

El centro de acopio actual está conformado por tres cajas estacionarias metálicas, se encuentra aproximadamente a 58 metros de la zona de playa, a 165 metros de la Ciénaga de La Virgen y a 400 metros del sector Caño Luisa; se cubre una demanda de almacenamiento de $6,78 \mathrm{~m}^{3}$. La figura 11 muestra las condiciones actuales del acopio y disposición inadecuada. 


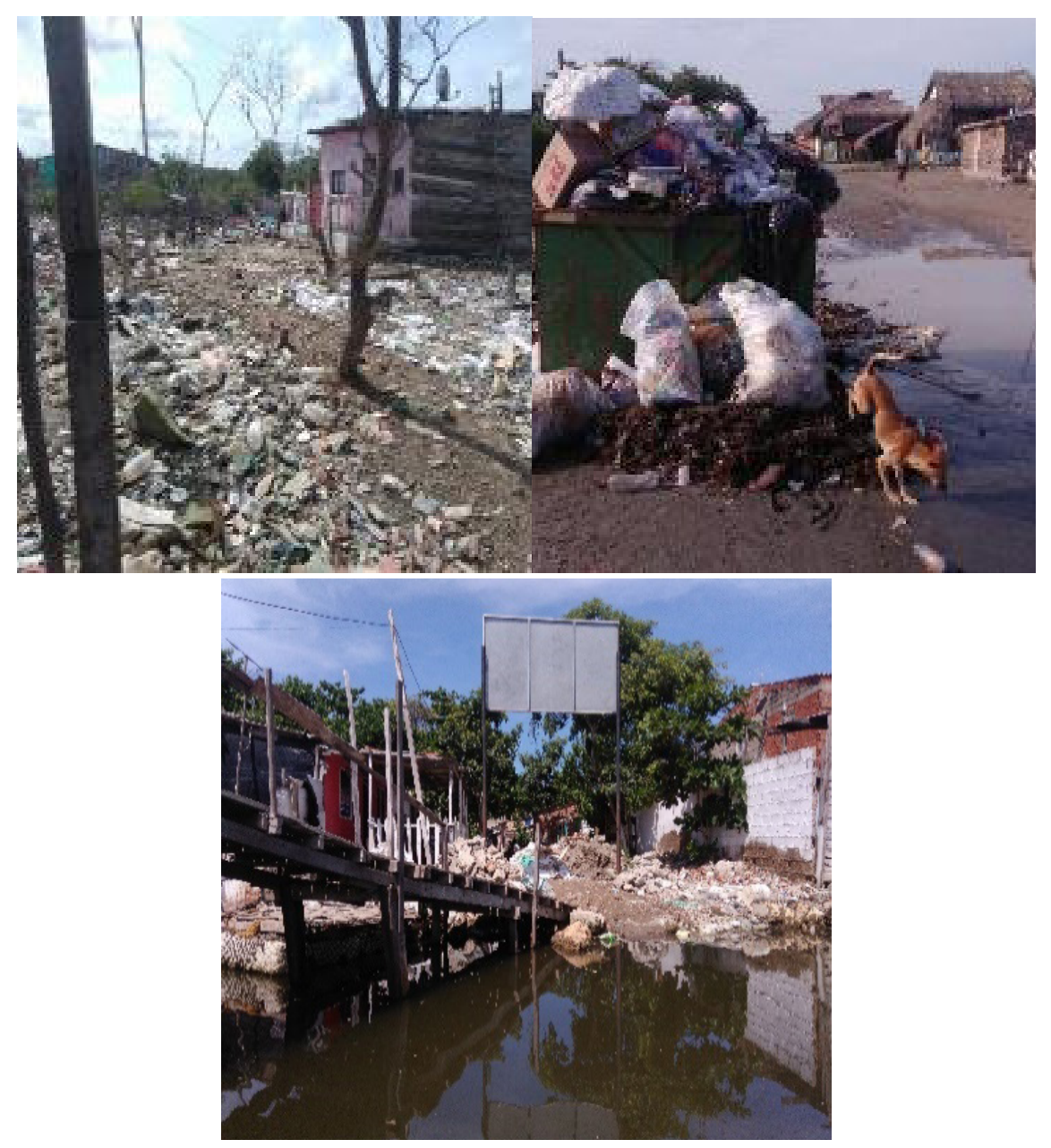

Figura 11. Estado actual del manejo de los residuos sólidos en el sector Caño Luisa

Se identificaron botaderos satélites ubicados en las orillas del cuerpo hídrico, en los patios y frente a las viviendas, lo cual representa una fuerte problemática ambiental destacando las siguientes:

- Incremento de materia orgánica y disminución del oxígeno disuelto, el cual es trascendente para la vida y desarrollo de las especies acuáticas.

- Taponamiento y represamiento de caudales por presencia de residuos como bolsas, escombros o cualquier elemento que obstruya el flujo normal del agua, en especial en época de lluvias. 
- Se amenaza la flora y la fauna acuática, y las actividades económicas relacionadas como la pesca y el turismo.

- Filtración de lixiviados a través del suelo, afectando la microbiota y cuerpos de agua cercanos.

- Dentro de los factores contemplados en el decreto 2981 de 2003, se destaca una insuficiencia de almacenamiento de los residuos sólidos respecto a la demanda actual, proliferación de vectores, depósito de aguas lluvias y humedad, y poca accesibilidad para los usuarios, específicamente del sector estudiado. Este último se convierte en el punto más crítico, pues es un factor influyente a la hora de lograr una mejora de las condiciones actuales de manejo de los residuos. Por tanto, se requiere de medidas que respondan a esta necesidad en particular.

\section{Plan de Manejo Integral de Residuos Sólidos propuesto}

Dado que hasta la fecha no se ha registrado la ejecución de medidas de manejo de residuos sólidos en el corregimiento de La Boquilla, en especial en el sector Caño Luisa, se propone la implementación de medidas tendientes al mejoramiento del servicio público de aseo en sus etapas de presentación (almacenamiento), recolección y transporte; con el fin de minimizar los impactos producidos por las problemáticas anteriormente desarrolladas. Entre las medidas se resaltan las siguientes:

\section{Almacenamiento temporal de residuos sólidos.}

Hace referencia al acopio temporal de los residuos sólidos en sitios previamente establecidos y acordados con los habitantes y con la empresa prestadora del servicio.

De acuerdo a las falencias identificadas del servicio público de aseo, la falta de gestión ambiental en la zona y el estudio de la demanda de almacenamiento de los residuos sólidos generados por los habitantes del sector Caño Luisa, se evidencia que existe la carencia de al menos dos centros de acopio adicionales en puntos más cercanos y accesibles para 
los habitantes, de tal forma que se minimice el trayecto hasta el punto de acopio actual ubicado a una distancia mínima de 450 metros, aproximadamente. Con esto se espera una mejora significativa de las condiciones de saneamiento y condiciones ambientales (Ver figura 12).

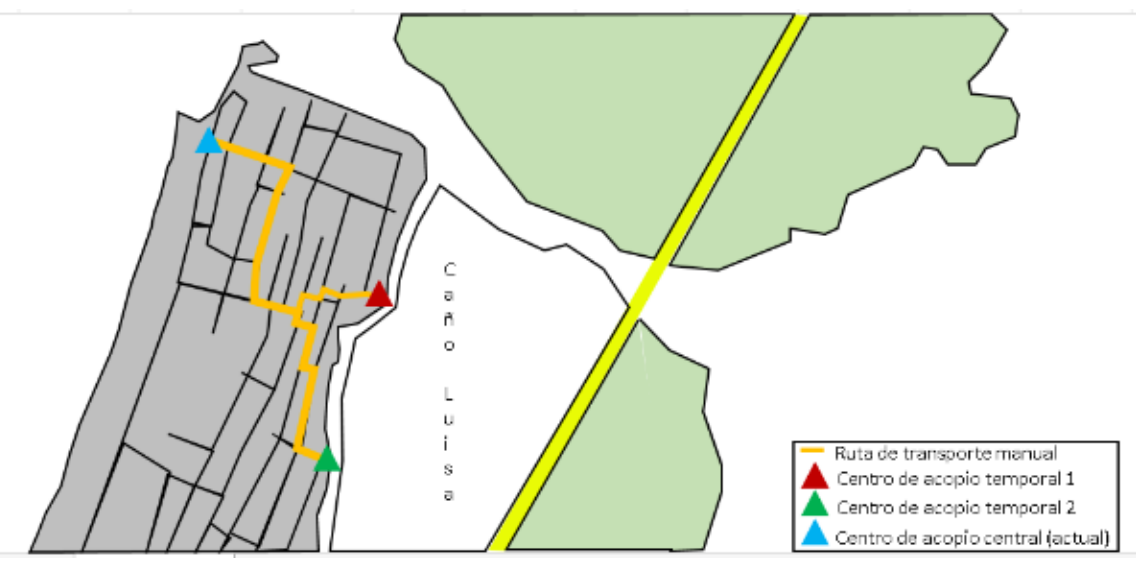

Figura 12. Centro de acopio temporal y microrruteo de recolección y transporte de los residuos sólidos, propuestos

Se trata del funcionamiento de dos centros de acopio adicionales, ubicados cerca de los dos puentes artesanales con que cuenta el sector. Además, se cuenta con un indicador de cumplimiento que permite la estimación de suficiencia de almacenamiento (S.A.) en las cajas estacionarias ubicadas en cada punto de acopio.

Indicador: suficiencia de almacenamiento

$$
\text { S. A. }=\frac{\text { kg de residuos solidos generados }}{\text { Capacidad de contenedores }}
$$

En este sentido, cada punto de acopio debe contar con una capacidad mínima de almacenamiento de $1,80 \mathrm{~m}^{3}$ para los residuos generados por los habitantes de Caño Luisa y para aquellos provenientes de sectores adyacentes que deseen hacer uso de este mecanismo con las indicaciones mostradas en la figura 13. 

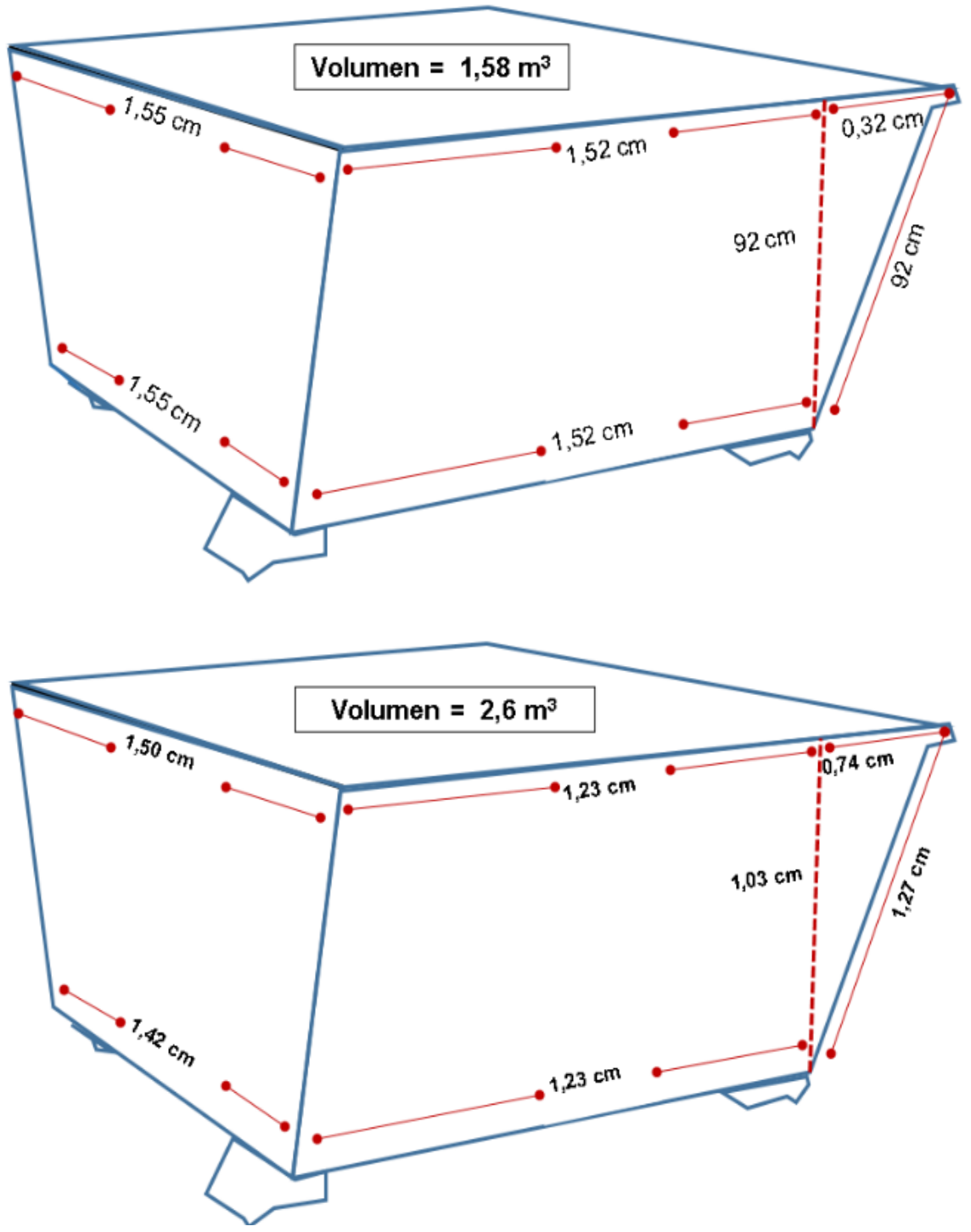

Figura 13. Dimensiones de los contenedores para el almacenamiento temporal de los residuos sólidos

Se sugiere el uso de contenedores cuyo material sea apropiado en cuanto a la naturaleza del territorio (polietileno de alta densidad) para evitar su corrosión y deterioro, la implementación de sellado para evitar la proliferación de vectores, humedad o lixiviación; y su respectiva señalización. 


\section{Recolección y transporte de residuos sólidos}

Se sugiere aglomerar los residuos en los sitios previamente acordados y señalizados, y cargarlos en los vehículos recolectores a través de microrrutas hasta el centro de acopio general para su posterior transporte hacia el sitio de disposición final, a cargo de la empresa Promoambiental del Caribe S.A. E.S.P.

En este caso se iniciará con una recolección general, con una frecuencia de tres veces por semana sin discriminar los residuos sólidos; sin embargo, se espera la implementación de una recolección discriminada con el fin de aprovechar los residuos con potencial de ser tratados o reciclados.

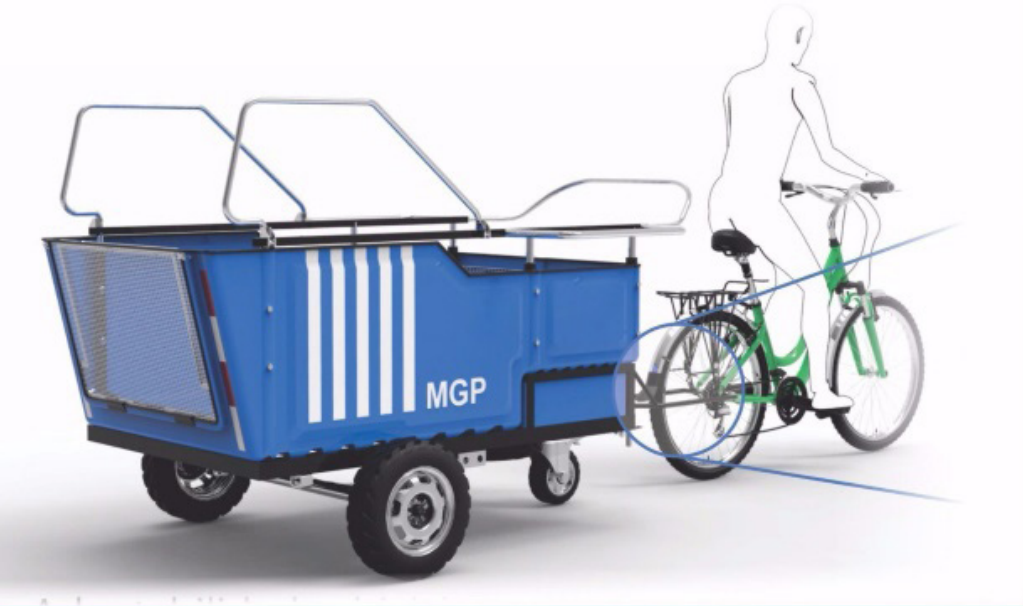

Figura 14. Vehículo propuesto

III. Propuesta de gestión para el aprovechamiento y/o reciclaje de residuos sólidos

Teniendo en cuenta que gran parte de la comunidad de la Boquilla, específicamente el sector Caño Luisa utiliza sus residuos sólidos para rellenar terreno perteneciente a los manglares y, posteriormente, construir sus viviendas trayendo consigo consecuencias importantes en la salud y el ambiente (agua, suelo y aire), la presente propuesta hace énfasis en la 
gestión para el aprovechamiento y/o tratamiento de los residuos sólidos, de tal manera que se minimice su disposición final inadecuada y se incentive a la reincorporación de los mismos al ciclo productivo, sirviendo como fuente de ingresos para las personas de la comunidad.

Las acciones propuestas parten de la necesidad de disminuir la cantidad de residuos que son generados y presentados para la disposición final, sabiendo que la mayoría de los residuos generados en la comunidad de Caño Luisa son orgánicos y plásticos, los cuales pueden ser aprovechados mediante reciclaje y compostaje.

El primer paso para la iniciación del programa es la participación activa de las comunidades, seguido de las autoridades competentes. El primero está en función de la participación de los ciudadanos en la etapa segregación, en la fuente y en la calidad de los productos obtenidos.

Teniendo en cuenta que los residuos orgánicos son los que se generan en mayor proporción, se plantea la posibilidad de desarrollar técnicas que permitan su aprovechamiento para el compostaje, generación de biogás, entre otros; mientras que los plásticos podrían ser reciclados o reutilizados.

IV. Propuesta de educación ambiental, sensibilización y capacitación ciudadana

Mediante esta propuesta se pretende atender las necesidades de difusión de conocimiento, orientación y concienciación a través de actividades, talleres y jornadas de sensibilización a la comunidad del sector Caño Luisa, y capacitaciones a aquellos involucrados en los programas de recolección, transporte, reciclaje y aprovechamiento, con el fin de garantizar la eficiencia y estabilidad de los mismos.

Se proponen actividades como la realización de talleres y actividades lúdicas que contribuyan a la formación ambiental referente a separación 
en la fuente, reciclaje y aprovechamiento de residuos; concientización sobre los impactos ambientales generados por el mal manejo de los residuos sólidos, y la realización de jornadas de limpieza con el fin de minimizar los puntos críticos de acumulación de residuos sólidos.

\section{Conclusiones}

La implementación del PMIRS en la comunidad de Caño Luisa permitirá cumplir con la normatividad ambiental nacional vigente y adquirir un mayor compromiso ambiental por parte de los habitantes de la comunidad.

De acuerdo con la información primaria obtenida, el nivel de educación se encuentra distribuido en educación secundaria (63\%), educación técnica (16\%), y el $21 \%$ no posee ningún nivel educativo. Por la naturaleza del territorio, la comunidad no cuenta con servicios públicos instalados directamente por una empresa prestadora de servicios, por lo que se abastece de agua potable y de energía eléctrica a través de conexiones informales desde la zona legalmente constituida del corregimiento de la Boquilla hasta las viviendas de la invasión. Además, el servicio de gas es a través de Cilindros de gas propano.

La producción per cápita calculada en la zona de estudio es de 0,46 0,85 $\mathrm{Kg} / \mathrm{hab} /$ día, mientras que la cifra de producción per cápita para Bolívar está alrededor de $0,85 \mathrm{Kg} / \mathrm{hab} /$ día; a pesar de estar por debajo de la PPC del departamento, el potencial impacto significativo de carácter negativo se deriva del vertimiento de los residuos sólidos al cuerpo de agua.

El plan de manejo integral de residuos sólidos de la comunidad de Caño Luisa plantea cuatro propuestas para implementación dirigidas a: almacenamiento temporal de residuos sólidos, recolección y transporte de residuos sólidos, gestión para el aprovechamiento y/o reciclaje de residuos sólidos y educación ambiental, sensibilización y capacitación ciudadana. 


\section{Referencias}

Brooks, G., Carroll, K., Butel, J., Morse, S., \& Mietzner, T. (s. f.). Microbiología médica. México: McGraw-HILL Interamericana editores S.A.25 edición. Disponible en: https://www.academia. edu/36581632/Microbiologia_Medica_Jawetz_25a_Edicion_ booksmedicos

Consejo Nacional de Política Económica y Social (CONPES, 21 de 11 de 2016). Política Nacional Para La Gestión Integral De Residuos Sólidos [en línea]. Disponible en http://www.andi.com.co/ Ambiental/SiteAssets/Paginas/default/CONPES\%203874.pdf

De Indias, A. M. D. C. (2001). Plan de Ordenamiento Territorial del Distrito Turístico y Cultural de Cartagena de Indias: síntesis del Diagnóstico. Secretaría de Planeación, Cartagena de Indias.

De Leo, F., Urzì, C. \& De Hoog, G. S. (2003). A new meristematic fungus, Pseudotaeniolina globosa. Antonie van Leeuwenhoek, 83(4), 351-360.

Departamento Administrativo Distrital de Salud (DADIS). (2007). Comportamiento de los eventos bajo vigilancia epidemiológica [en línea]. Recuperado de https://juanfe.org/wp-content/ uploads/2013/03/Epidemiologia-Cartagena-2007.pdf [Consultado el 03 de agosto de 2017].

Domiciliarios, S. D. S. P. (2018). Informe de Disposición Final de Residuos Sólidos - 2017. Informe Nacional. Bogotá DC diciembre de 2018, p. 34.

Ministerio de Ambiente, Vivienda y Desarrollo Territorial (MAVDT), CARDIQUE y Conservación internacional Colombia. (2004). Plan de ordenamiento y manejo de la cuenca hidrográfica de la Ciénaga de la Virgen, (Bolívar-Colombia). Recuperado de file:///C:/ Users/Usuario/Downloads/01 pomchcinagadelavirgeninformefinal-110116154142-phpapp02.pdf

Ministerio de Ambiente, Vivienda y Desarrollo Territorial. (2005). Guía para elaborar el Plan Integral de Residuos Sólidos: municipios menores de 50.000 habitantes. UNICEF. 
Municipalidad Distrital de Comas. (Junio de 2014). Estudio de carcaterización de residuos sólidos dimiciliarios del distrito de Comas [en línea]. Recuperado de http://www.municomas.gob.pe/anuncios/ Estudio_de_Caracterizacion_de_Residuos_domiciliarios.pdf

Superintendencia de Servicios Públicos Domiciliarios. Informe de la Superintendencia de Servicios Públicos Domiciliarios (2018). Disponible en https://www.superservicios.gov.co/nuestra-entidad/ planeacion/informes-gestion

UNFPA. (2016). Estado de la población mundial 2016 [en línea]. Disponible en http://colombia.unfpa.org/sites/default/files/pubpdf/ SP_SWOP\%202016\%20report.pdf 